\title{
EXPERIENCIAS OBTENIDAS DEL EMPLEO DE LOS DIFERENTES TIPOS DE MUROS CORTINA
}

\author{
ESPAÑA
}

\author{
(EXPERIENCES OBTAINED FROM THE USE OF DIFFERENT TYPES OF \\ CURTAIN WALLS. SPAIN)
}

José Ramón Azpiazu Ordóñez, Dr. Arquitecto

\section{RESUMEN}

Hoy dia la fachada construida con muro cortina de perfiles de aluminio lacado y vidrio no tiene problemas.

Su estanquidad está garantizada y con los vidrios Climalit o Termophane de 6/12/6, 8/12/6, o 6/12/6/12/6 $\mathrm{mm}$, según los casos, el aislamiento acústico y calorifico está resuelto.

Estructuralmente podemos distinguir las variantes siguientes (ver gráfico, página 21):

$10^{\circ}$-Perfiles vistos en las cuatro direcciones.

$2^{\circ}$ - Perfiles vistos en dirección horizontal y ocultos en vertical (silicona estructural a dos caras).

$33^{\circ}$ - Perfiles vistos en dirección vertical y ocultos en horizontal (silicona estructural a dos caras).

4. - Perfiles ocultos (silicona estructural a cuatro caras).

El sistema más seguro estructuralmente es el primero y se recomienda sobre todo en fachadas de curvatura muy acusada, que al descomponerlas en poliedros inscritos forman ángulos muy pronunciados entre las caras contiguas.

Para edificios que se quiera dar sensación de horizontalidad emplearemos el $2^{\circ}$ y si se quiere dar sensación de verticalidad el 3 . $^{\circ}$

Cuando tratemos de conseguir un edificio de altura, que pese lo menos posible y flote entre las nubes, emplearemos el $4 .^{\circ}$ sistema.

Este último sistema representa la antitesis de Mies Van Der Rohe de marcar la estructura en el exterior hasta el límite.

\section{SUMMARY}

Nowdays, the façade built of curtain walls made of varnished aluminium profiles and glass presents no problem.

Its watertightness is guaranteed and with the Climalit and Termophane glasses of 6/12/6, 8/12/6 o $6 / 12 / 6 / 12 / 6 \mathrm{~mm}$ depending on the case, the acoustic and heat insulations are resolved.

Structurally, we can distinguish the following variants: (see the graphic on page 21).

$10^{\circ}$ - Profiles seen in four directions.

$2 .^{\circ}$-Profiles seen in the horizontal direction and hidden in the vertical direction (structural two face silicone).

$3^{\circ}-$ Profiles seen in the vertical direction and hidden in the horizontal direction (structural two face silicone).

$4 .^{\circ}$-Hidden profiles (structural four face silicone).

The system which is structurally the safest is the first one and it is recommended especially for the façades of a very marked curvature, which, when decomposed to registered polyhedrons, from very pronounced angles between contiguous sides.

For buildings in which we want to achieve a sensation of horizontally, we will use the system n.. 2 and in case the sensation of verticality is sought, the $n^{\circ} 3$ will be used.

When trying to get a tall building weighing as little as possible and floating in the clouds, we use the system n.. 4

The last one represents Mies Van Der Rohe's antithesis for marking the structure on the outside as much as possible. 


\title{
EDIFICIO DE OFICINAS EN LA AVDA. DE LA PAZ, MADRID
}

\author{
José Ramón Azpiazu Ordóñez, Manuel Ayllón Campillo y
}

Jaime Ferrer Sarroca, Arquitectos

Está situado en el Polígono 7 de la Avda. de La Paz. Forma parte del A.P.D. ordenado por la Gerencia Municipal de Urbanismo. Da fachada a la cuesta del Sagrado Corazón y a la M 30.

Se compone de 4 edificios de formas curvas y rectas que limitan una calle interior de acceso con una plaza circular en fondo de saco.
El conjunto de edificios está distribuido a través de 7 portales.

Los edificios tienen dos plantas de sótano destinadas a garajes; planta baja con porche de acceso; planta primera reducida por ser el porche de doble altura; planta segunda, tercera, cuarta y quinta completas; planta sexta reducida por la circulación de las góndo.

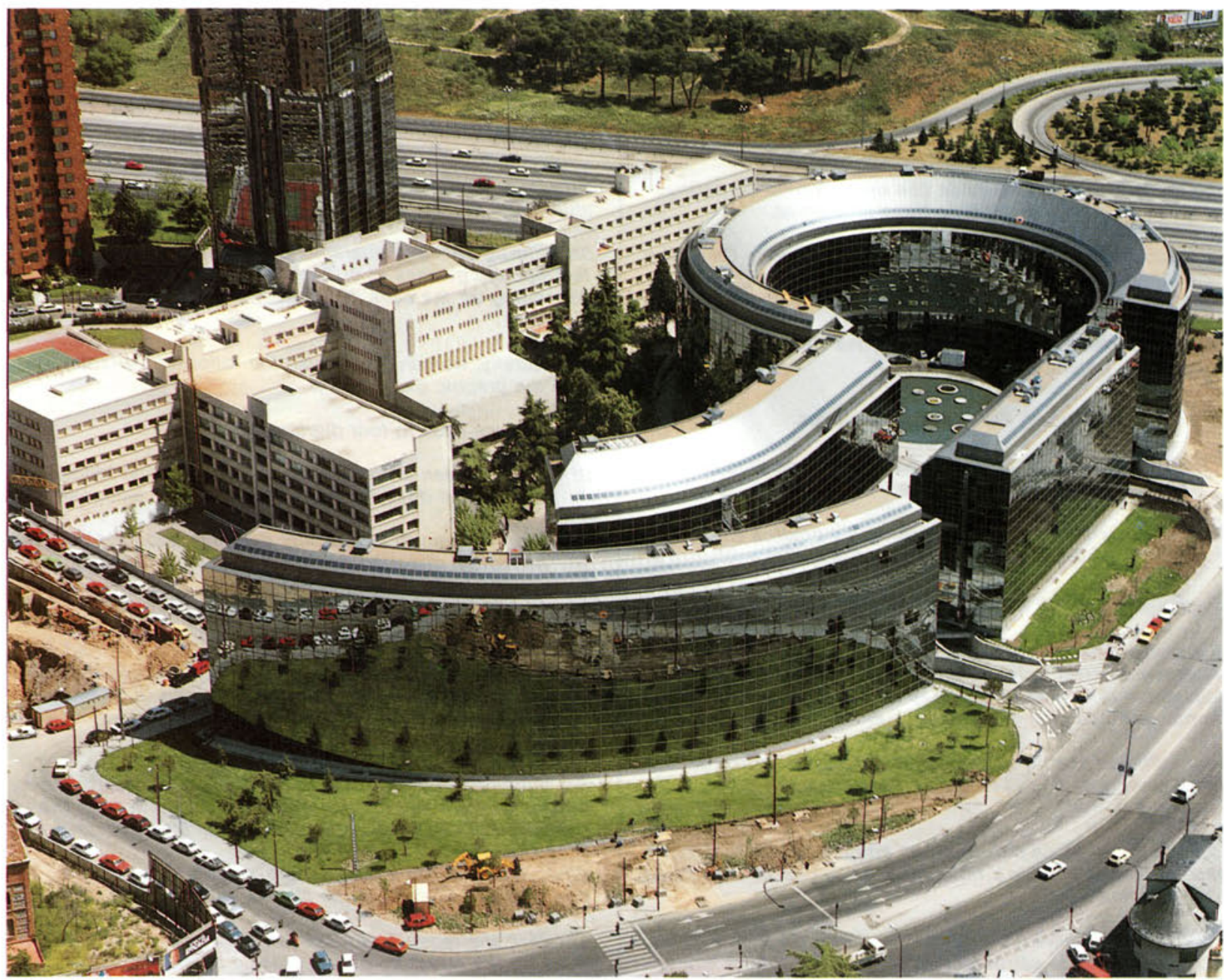

Vista aérea del conjunto. 
las, y planta bajo cubierta destinada a instalaciones, archivos y pequeños despachos.

El destino del edificio es exclusivo de oficinas.

Los siete portales dan a la calle interior y las puertas de acceso están situadas dentro del porche.

A los garajes se accede a través de rampas, dos dan a la cuesta del Sagrado Corazón y una a la calle particular.

Alrededor del edificio se ha dispuesto un jardín con césped, gran variedad de coniferas de hoja perenne, castaños de indias y magnolios. En el centro de la plaza circular se ha situado una fuente múltiple con jardineras circulares de vivaces y estanque de agua.

Los materiales empleados son los siguientes:

- Estructura de hormigón armado.

- Fachada muro cortina de perfiles vistos de aluminio lacado y vidrio Termophane Spectrum color plata $(1 / 4 " \cdot 1 / 2 " \cdot 1 / 4 ")$.

- Cubierta formada por placas de aluminio y ventanales del mismo material.

- Pavimentos exteriores de losas de granito gris abujardadas y pavimento de portales de granito gris pulido.

- Pavimento de escaleras y aseos de mármol Rosa Sarci, el revestimiento de paredes de aseos del mismo material y el chapado de las paredes laterales de la escalera de madera lacada.

- Repisas continuas de lavabos de mármol blanco portugués.

- El pavimento de las oficinas es de moqueta cortada en baldosas.

- Los falsos techos son practicables con luminarias empotradas.

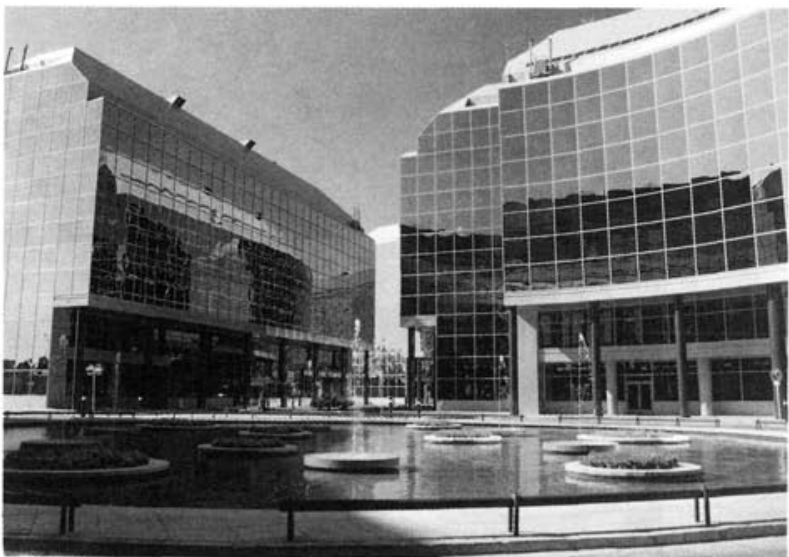

Vista interior de la plaza mostrando el estanque central.

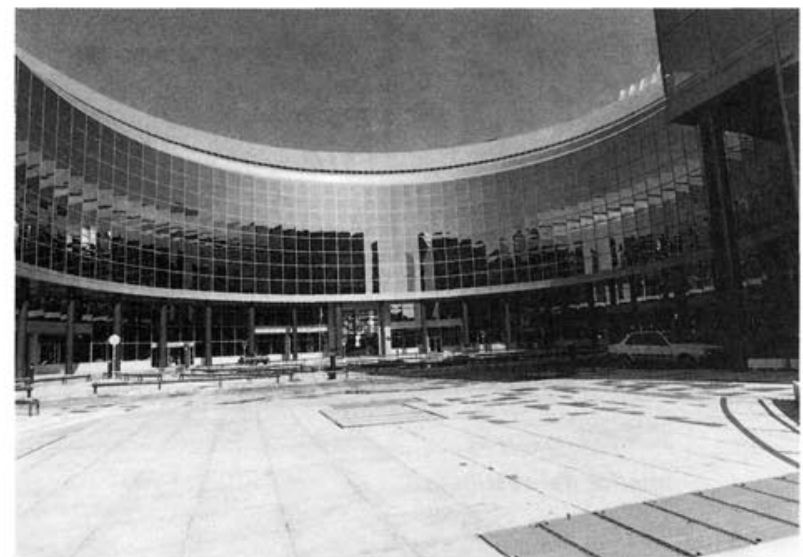

Vista interior.

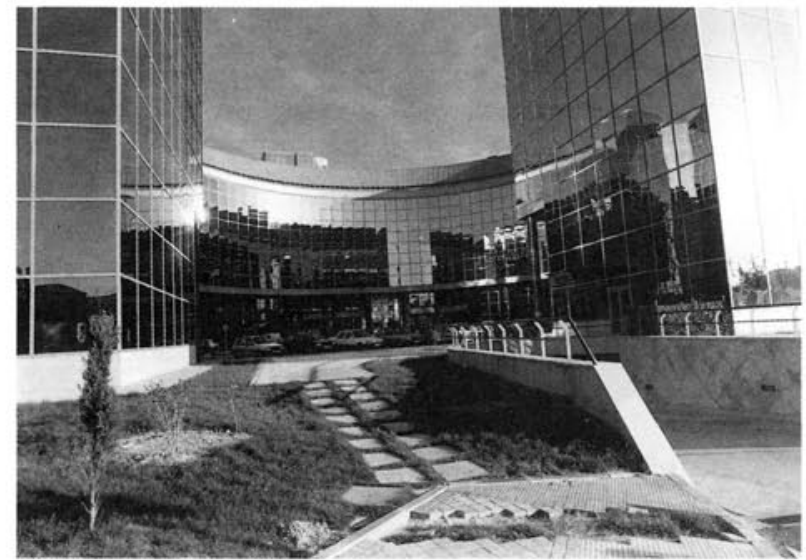

Vista de una de las entradas de acceso al garaje. 


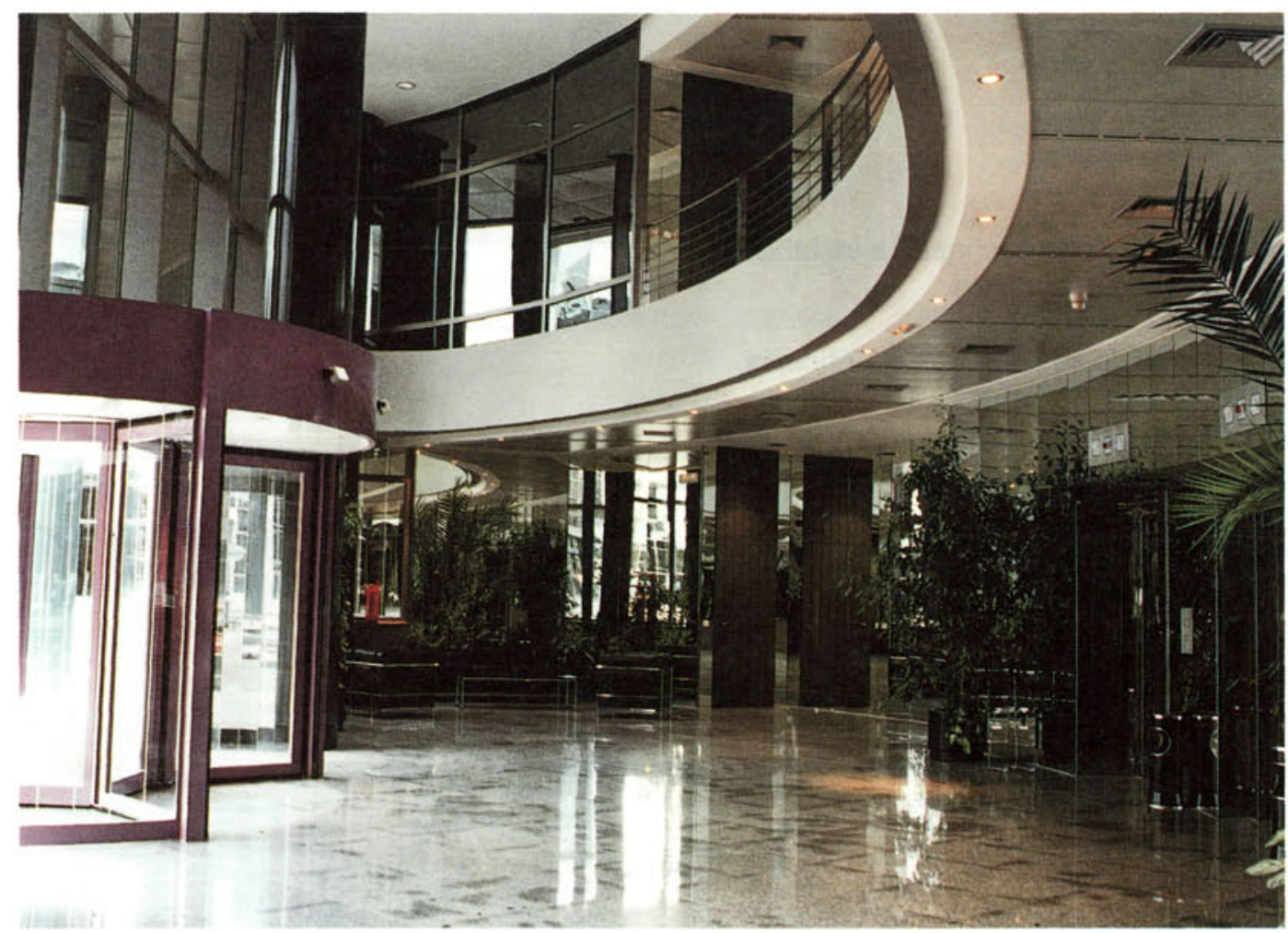

Interior del vestíbulo.






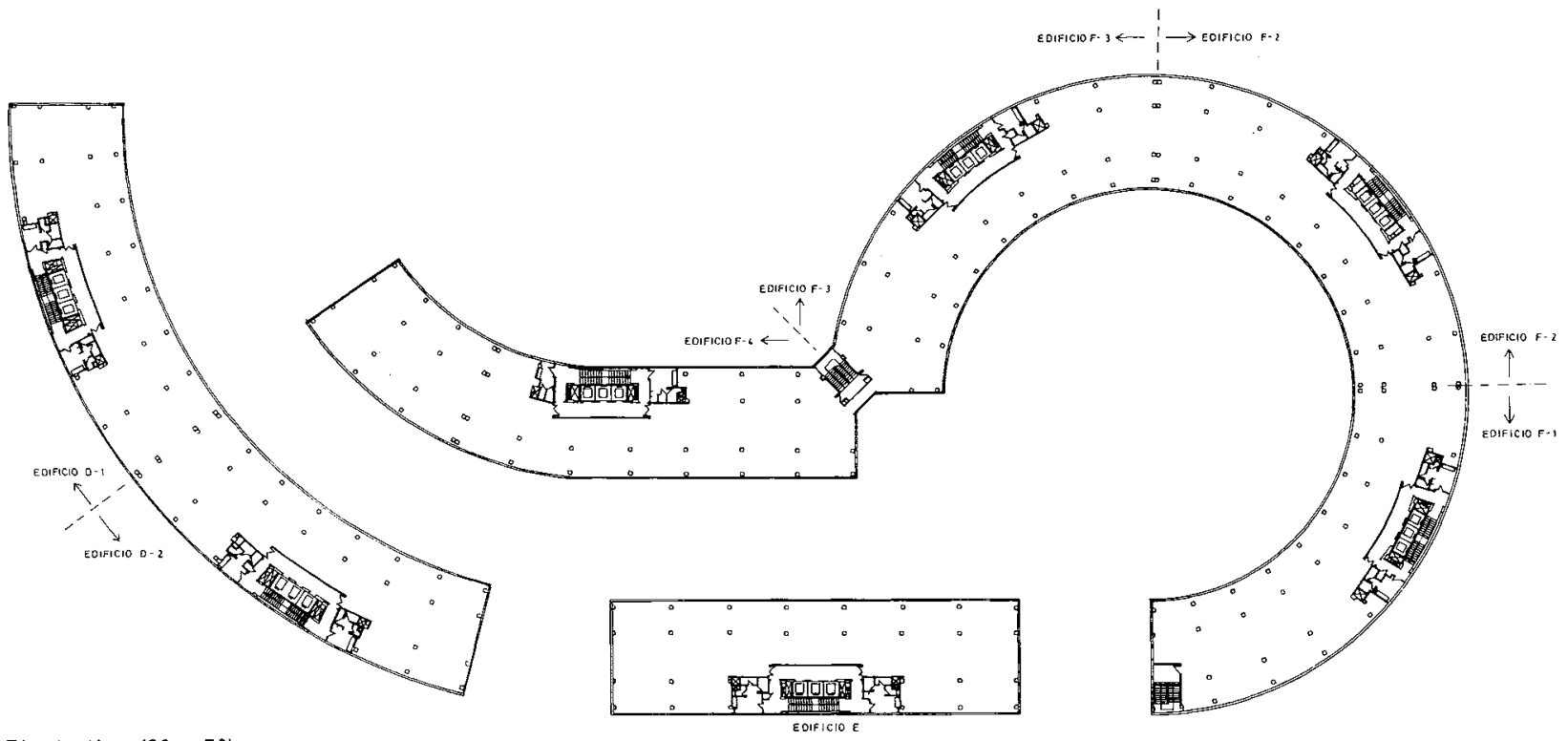

Planta tipo $\left(2^{\mathrm{a}}\right.$ a $\left.5^{\mathrm{a}}\right)$.

$\stackrel{2}{1020}$

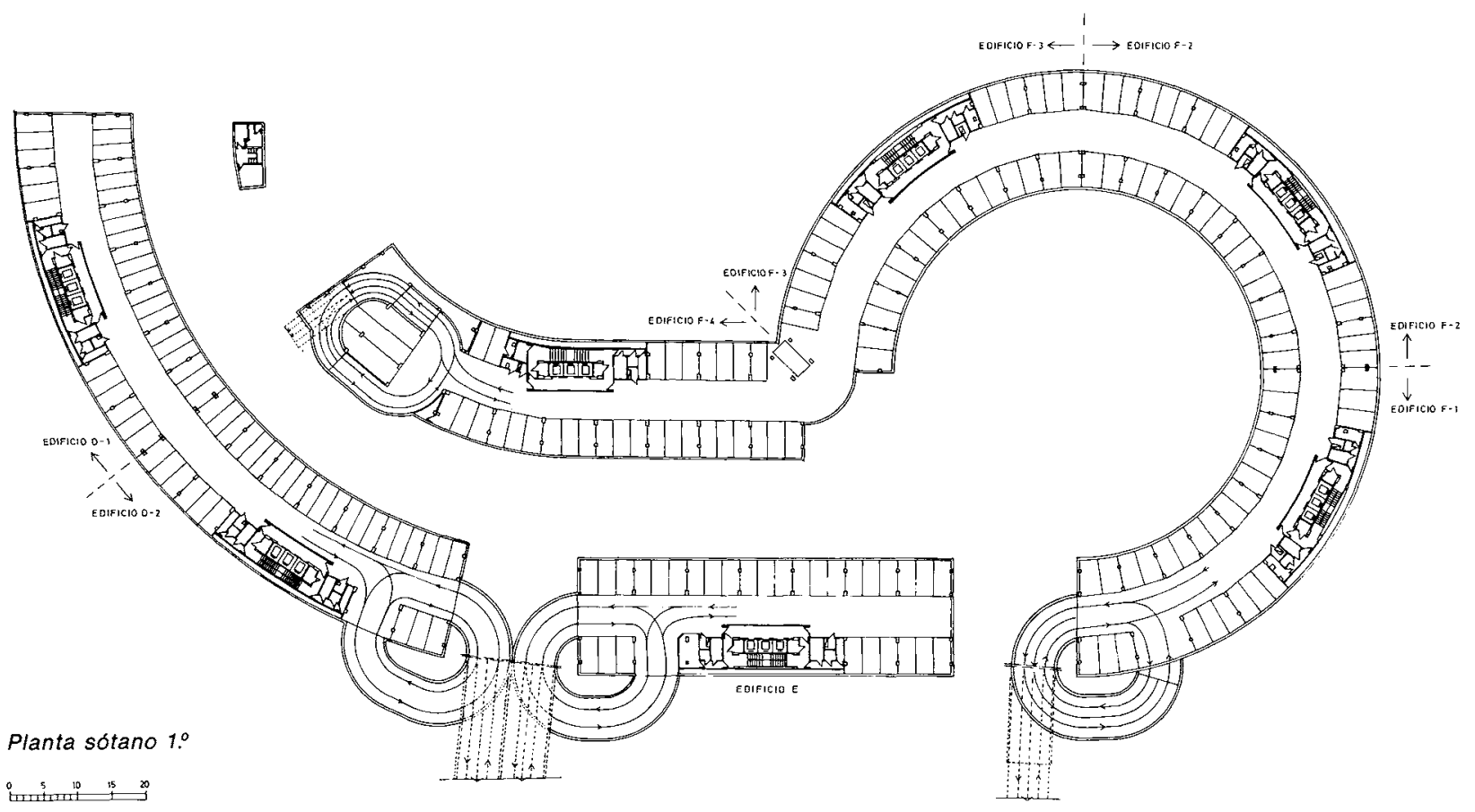



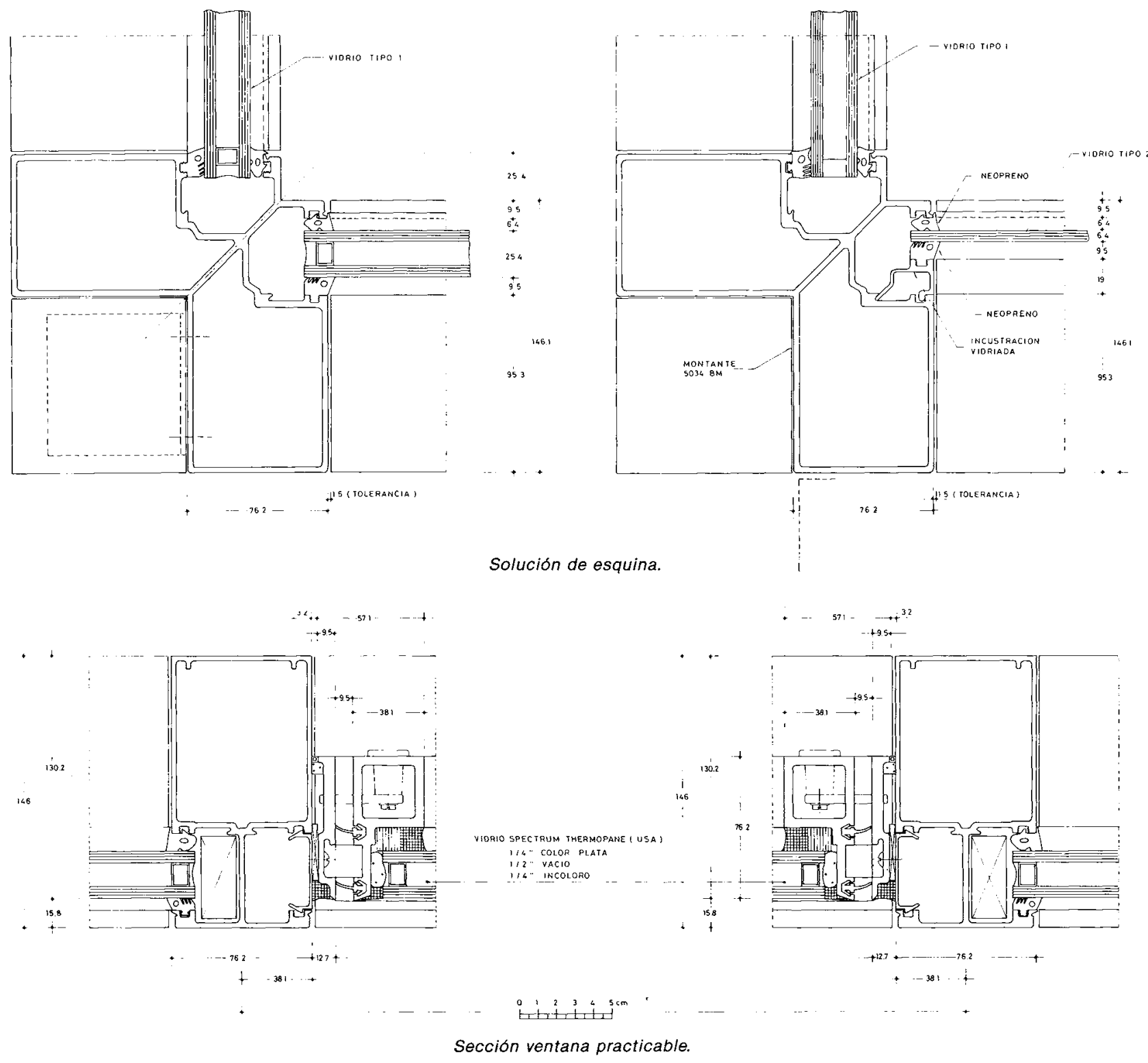

Como instalaciones importantes se pueden citar:

- Aire acondicionado con fuente de energía bomba de calor, Fancoils a cuatro tubos situados a lo largo del perímetro de los falsos techos e impulsión de aire de volumen variable en el centro de los mismos.

- Ascensores de $1 \mathrm{~m} / \mathrm{s}$ de velocidad, micronivelación maniobra combinada, sistema de regulación automático manual y memoria.

- Puertas de acceso de chapa metálica y paneles de vidrio, circulares y accionadas por célula fotoeléctrica.

- Suelos flotantes con red instalada.

- Grupo electrógeno.
- Detección de monóxido de carbono.

- Detección de incendios.

- Grupo de presión y algibes bajo las rampas de garajes.

\section{Grado de inteligencia del edificio}

Control por ordenador:

- Ascensores, puesta en marcha, parada y detección de averias.

- Grupo electrógeno, puesta en marcha y parada.

- Aire acondicionado, puesta en marcha y parada por zonas y detección de averias. 

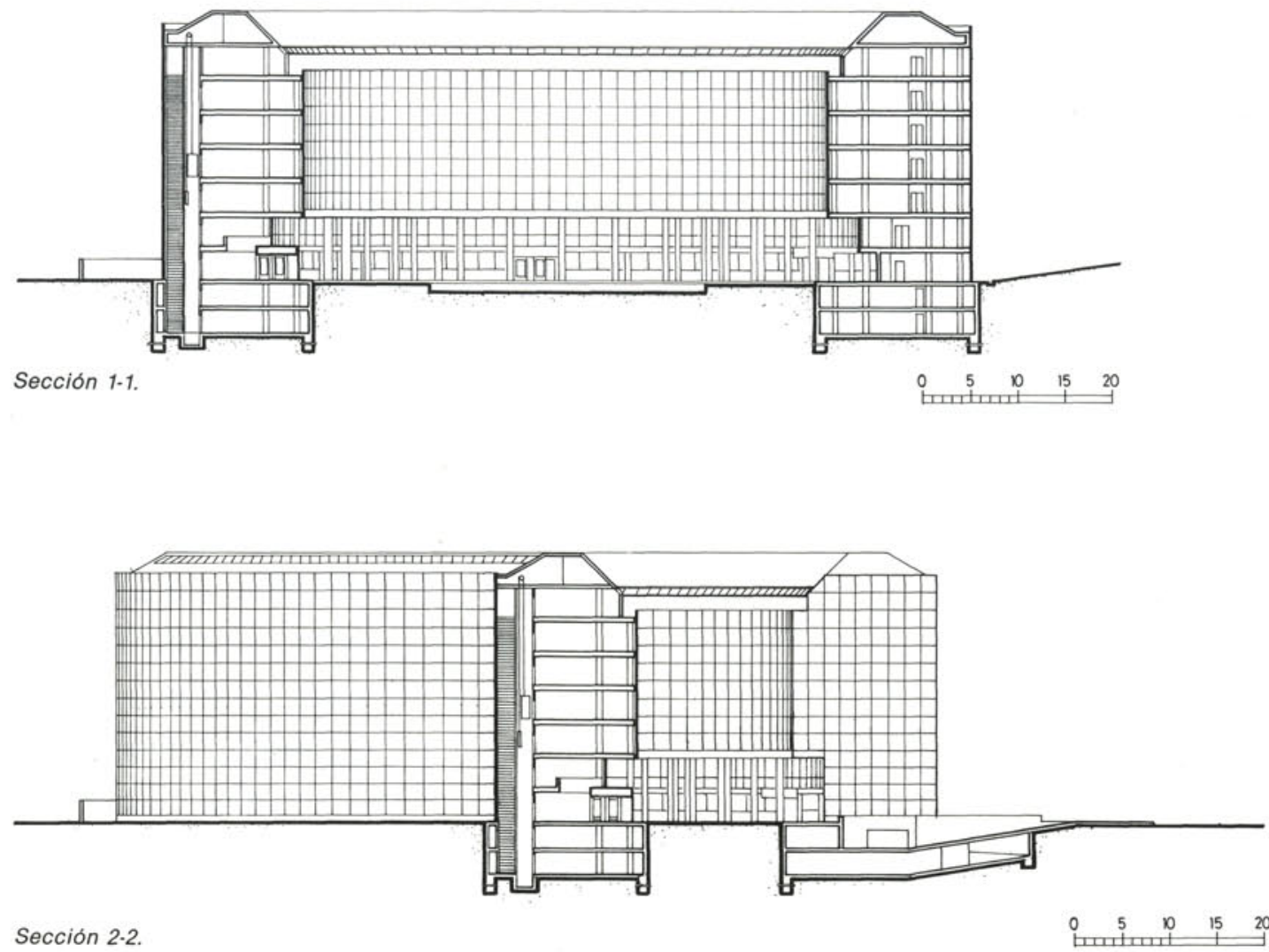

- Detección monóxido de carbono en garajes.

- Detección de incendios.

Está preparado para controlar por ordenador las salidas y las entradas.

En la decoración de los portales se ha procurado combinar el muro cortina que penetra desde fuera con revestimiento de espejos, puertas de ascensores de acero inoxidable y puertas de oficinas metálicas revestidas de madera lacada.

El efecto que se pretende es aumentar las dimensiones de los espacios. El interior de las cabinas de los ascensores va revestido en su totalidad de espejos seccionados en ángulo, que contribuyen a multiplicar las imágenes dando al espacio interior sensación de grandiosidad.

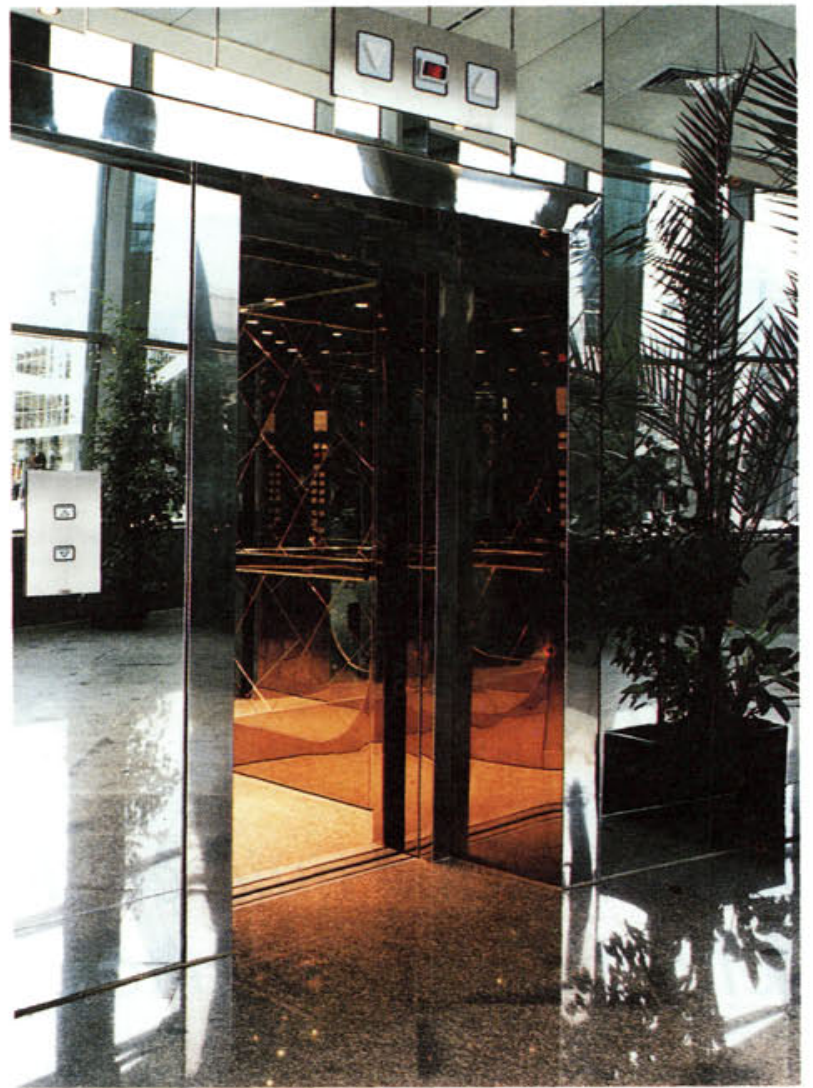




\section{OTIS EN LA EXPPO'}

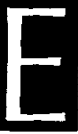

n la Expo'92, OTIS va a dejar el pabellón de muchos países bien alto.

Es una gran responsabilidad que no se puede confiar a cualquier marca. Por eso, obras tan relevantes como los pabeIlones de EE.UU., Inglaterra, Alemania, Francia, Japón, Suecia, Holanda, Dinamarca, Nueva Zelanda, España, Andalucía, Rank Xerox, Redesa, Cruz Campo y los de muchos países y entidades más, han confiado a OTIS sus instalaciones de transporte vertical.

$Y$ es que, a estas alturas, es preferible subir con el líder.

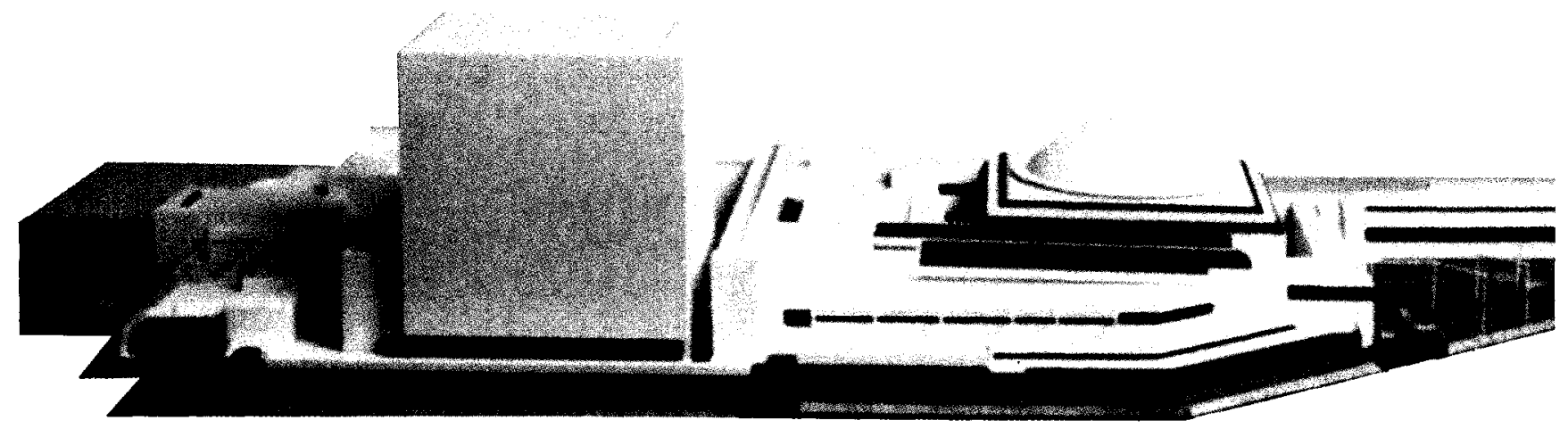

para los que quieren dejar el pabellón bien alto.



ZARDOYA OTIS, S.A.

Plaza del Liceo, 3 - Tel.: 7591000 28043 MADRID 


\title{
EDIFICIO DE OFICINAS EN LA CI. PRINCIPE DE VERGARA, MADRID
}

\author{
José Ramón Azpiazu Ordóñez, Arquitecto
}

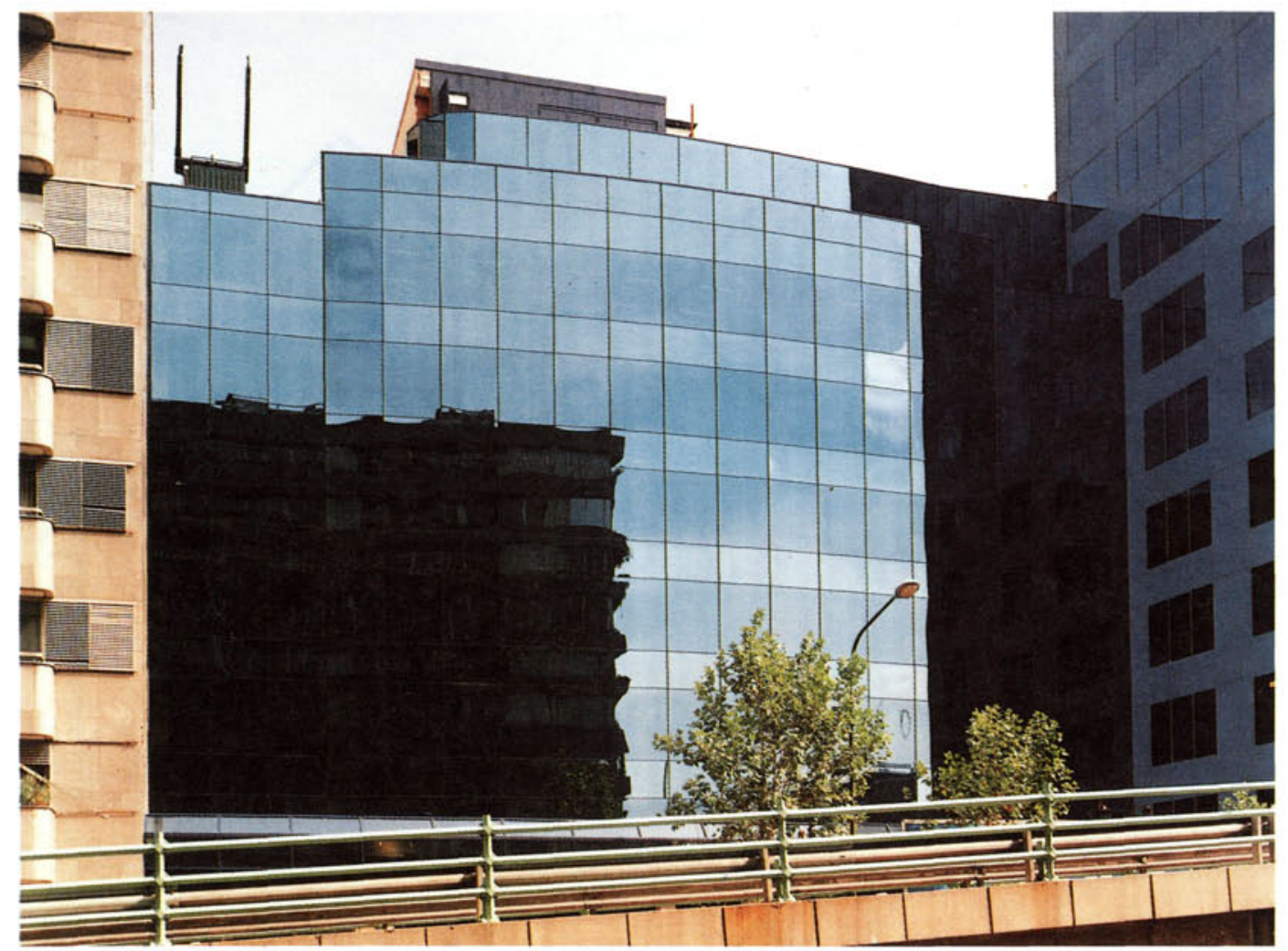

Fachada a la Cl. Príncipe de Vergara.

Está situado en la calle Príncipe de Vergara semiesquina a Francisco Silvela. Forma parte de un A.P.D. ordenado por la Gerencia Municipal de Urbanismo.

La planta es de forma poligonal e irregular con facha. das a la calle Príncipe de Vergara, Pinilla del Valle y D.M. de La Alameda.

El Edificio consta de cuatro plantas de sótano desti- nadas a garaje, planta baja compuesta por portal de acceso y locales comerciales, ocho plantas de oficinas y torreón de instalaciones.

Debido al gran desnivel existente, entre las calles que circundan el solar, se dispuso el acceso principal al Edificio por la calle Príncipe de Vergara, consiguiendo un acceso secundario desde las otras calles a través de la segunda planta. 



Planta sótano $1^{\circ}$

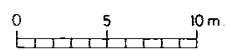

Planta sótano tipo.
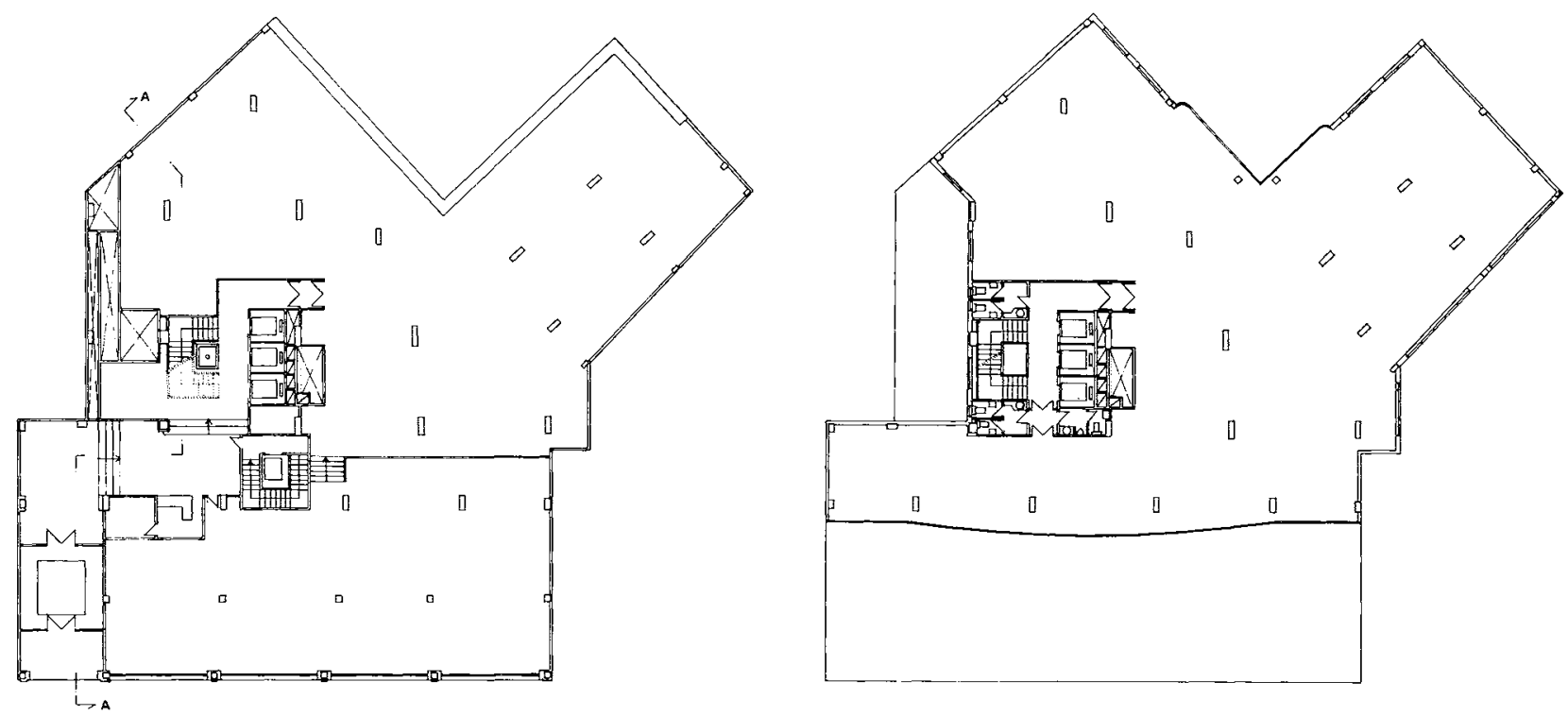

Planta baja.

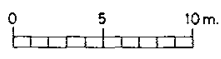

Planta tipo.

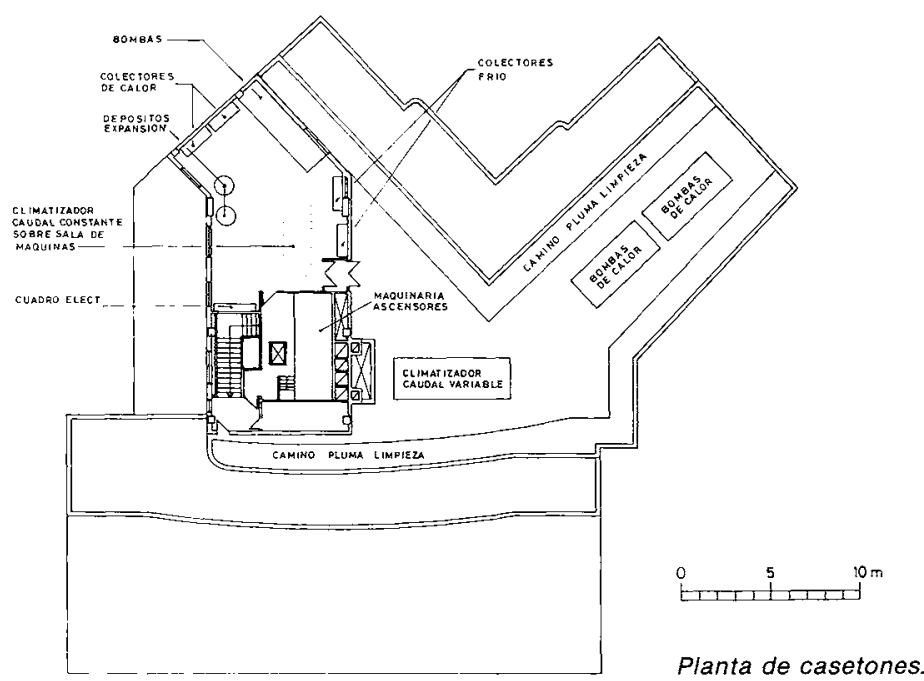


El garaje forma parte de un garaje común de manzana, teniendo el acceso a través del edificio de la esquina.

Como esquema de organización en planta se establecen todos los accesos, tanto verticales como horizontales, en la parte lateral izquierda del Edificio, para no tener que usar espacios residuales de pequeñas dimensiones.

Los sótanos están distribuidos en dos niveles, con dos rampas en los extremos izquierdo y derecho del solar.

Existen dos escaleras, la principal que une la planta baja con la cubierta y la escalera correspondiente a los garajes que va de la planta baja al sotano cuarto.

La escalera principal está asistida por tres ascensores, con capacidad para seis personas, y la escalera secundaria por un ascensor hidráulico.

Al proyectar las fachadas se optó por una solución que decanta que el aspecto interior del Edificio corresponde a la función interior del mismo, siguiendo una concepción clásica dentro de las corrientes de la arquitectura actual.

Al escoger el colorido general se ha tenido en cuenta el edificio de la esquina, ya construido cuando se comenzó esta obra.

En la decoración del vestíbulo se ha procurado dar gran espaciosidad, utilizando revestimientos laterales de espejos, ya que el vestíbulo tiene mucha profundidad y no es excesivamente ancho.

\section{Materiales empleados}

- Estructura de hormigón armado.

- Fachada muro cortina de perfiles ocultos de aluminio lacado, silicona estructural a cuatro caras y vidrio color azul $(8 \mathrm{~mm} \cdot 12 \mathrm{~mm} \cdot 6 \mathrm{~mm})$.

- Pavimento del vestíbulo de granito pulido sueco azul negro. Pavimento de escaleras de mármol de Carrara blanco. Pavimento de oficinas de moqueta.

- Frente de ascensores de acero inoxidable con jambas de plástico negro.

- Falsos techos metálicos perforados, practicables con luminarias empotradas.



Interior del vestíbulo.

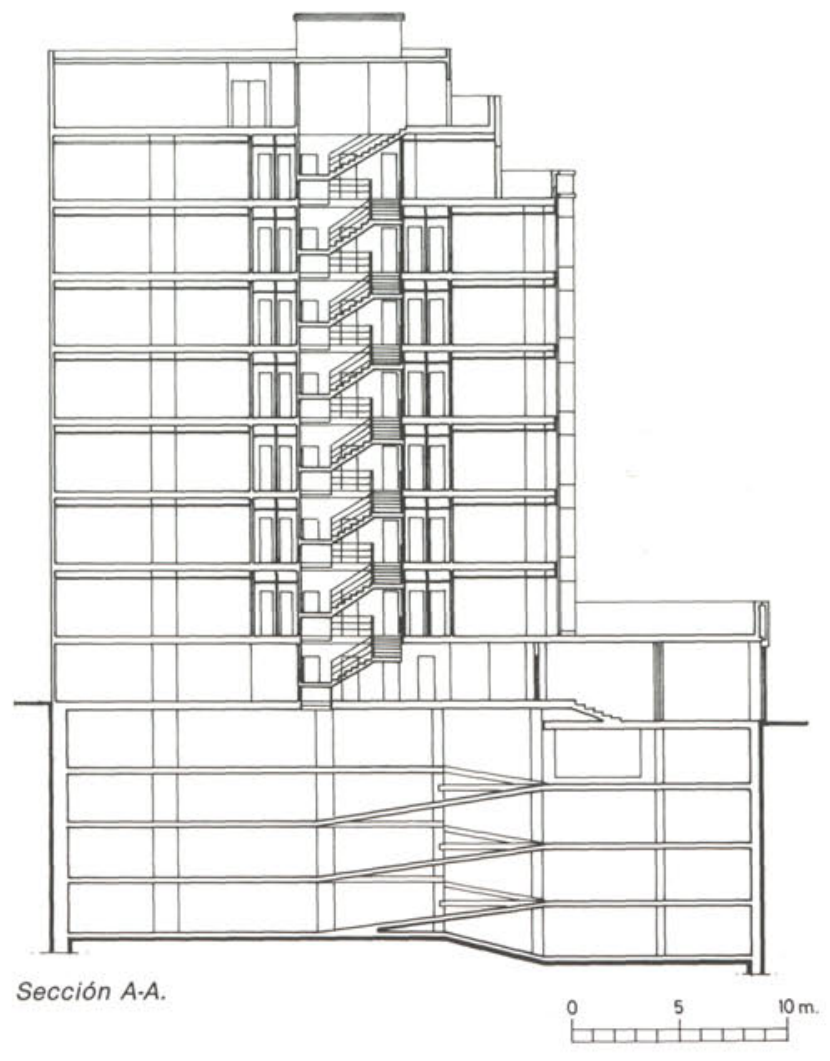



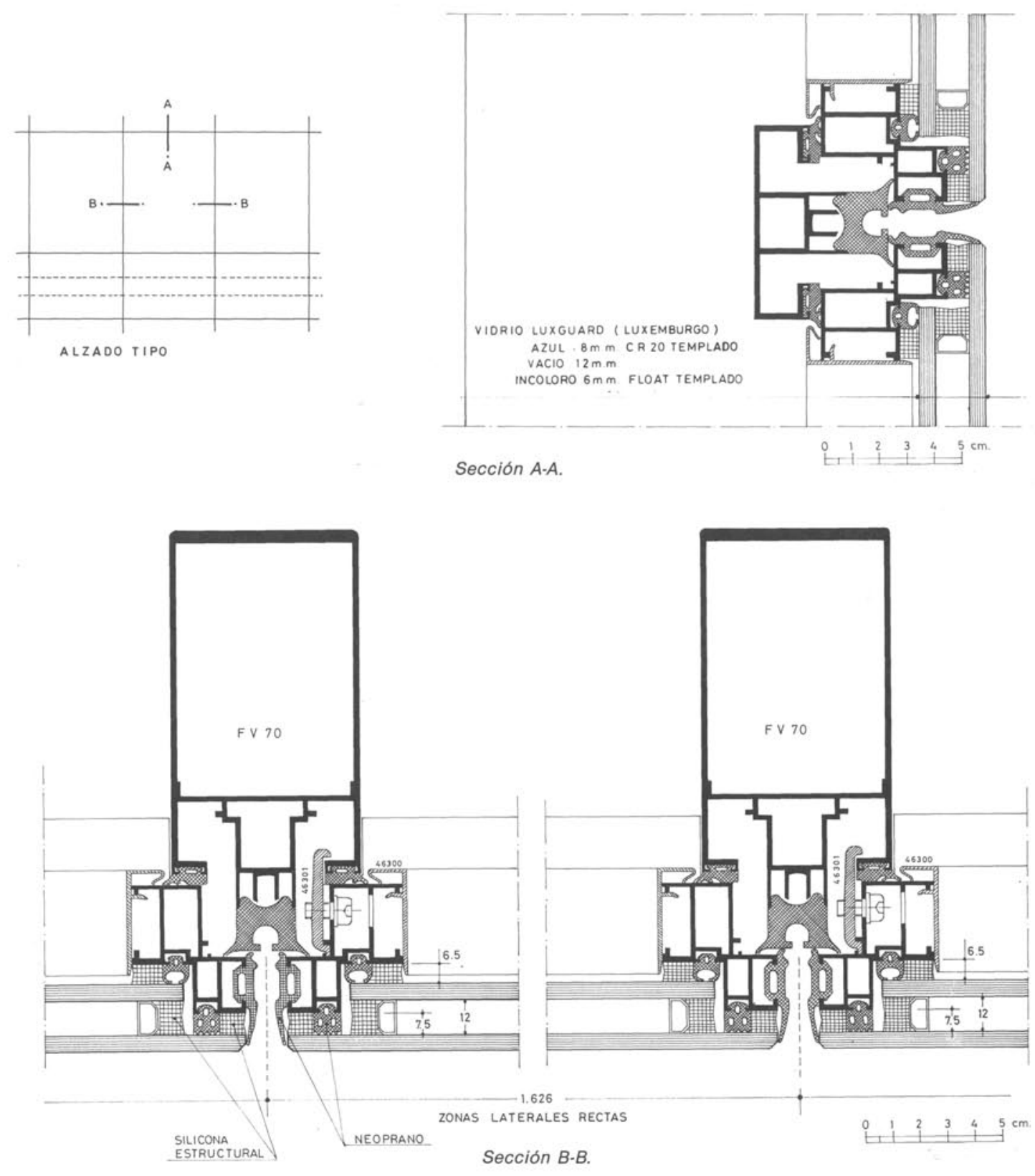

\section{Instalaciones importantes}

- Aire acondicionado con fuente de energía bomba de calor, Fancoils a cuatro tubos situados a lo largo del perimetro de los falsos techos e impulsión de aire de volumen variable en el centro de los mismos.

- Ascensores de 1/ms de velocidad, micronivelación, maniobra combinada, regulación automática y manual y memoria.

- Instalación eléctrica en falsos techos practicables y por canaletas embebidas en el forjado con distribución de energía eléctrica, teléfono y redes informáticas.
- Grupo electrógeno.

- Detección de monóxido de carbono.

- Detección y extinción de incendios.

- Grupo de presión y algibes.

\section{Grado de inteligencia del Edificio}

Control por ordenador de aire acondicionado, puesta en marcha, parada y detección de averías.

Detección de monóxido de carbono y detección y extinción de incendios. 


\title{
EDIFICIO ESPACIO, ALICANTE
}

\author{
José Ramón Azpiazu Ordóñez, Juan Salvador Pérez Parra y \\ José Luis Frías Wamba, Arquitectos
}

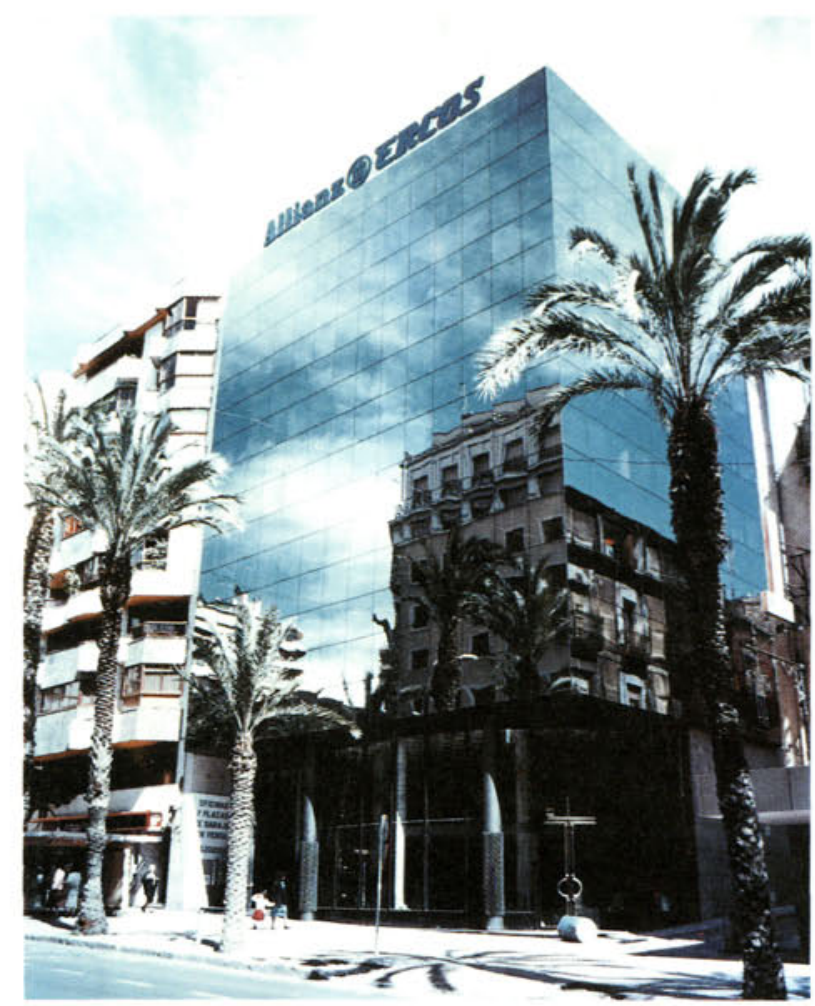

Fachada a la Rambla de Méndez Núñez.

Está situado en la Rambla Méndez Núñez, 30-32 de Alicante. Hace esquina con la calle San Isidro y su fachada superior da al callejón de San Andrés.

La planta es de forma rectangular y el Edificio consta de tres plantas de sótanos destinadas a garaje, planta baja y entreplanta de locales comerciales, siete plantas de oficinas y torreón de instalaciones.
A los garajes se accede a través de un elevador de vehiculos que tiene su entrada por la calle San Isidro, y el acceso principal de Edificio por la Rambla de Méndez Núñez a través de un pequeño porche.

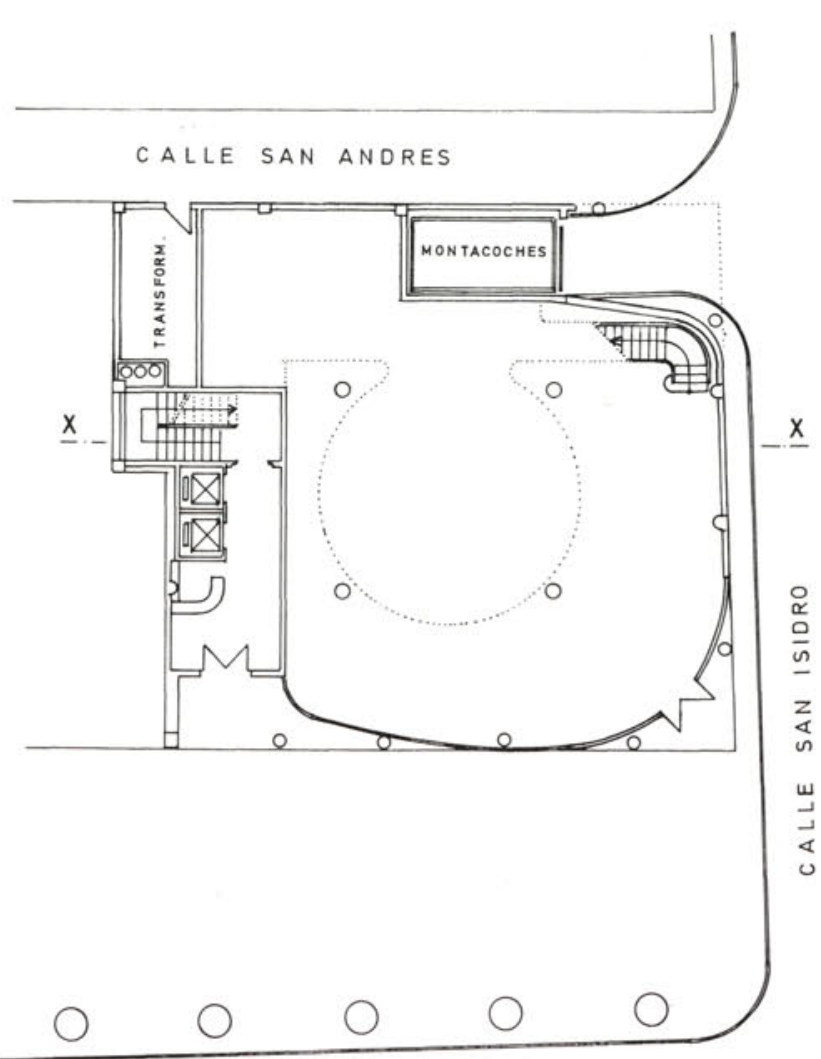

RAMBLA DE MENDEZ NUNEZ

Planta baja. 


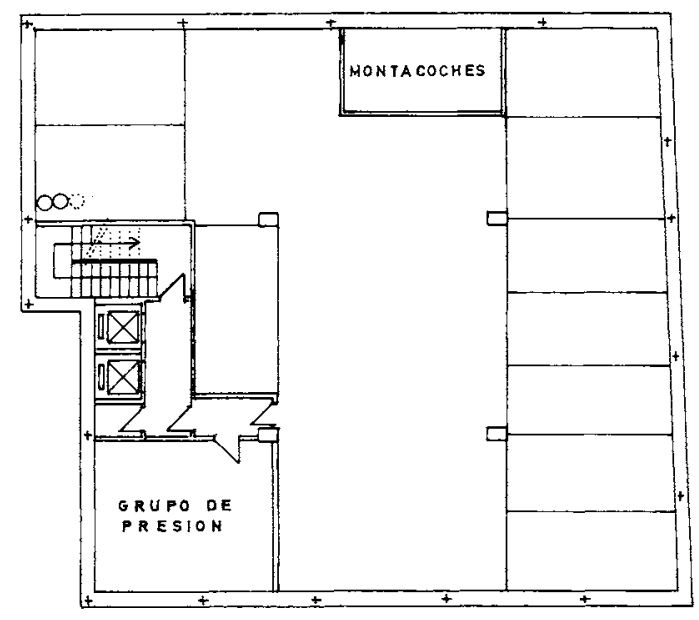

Planta sótano $1 .^{\circ}$

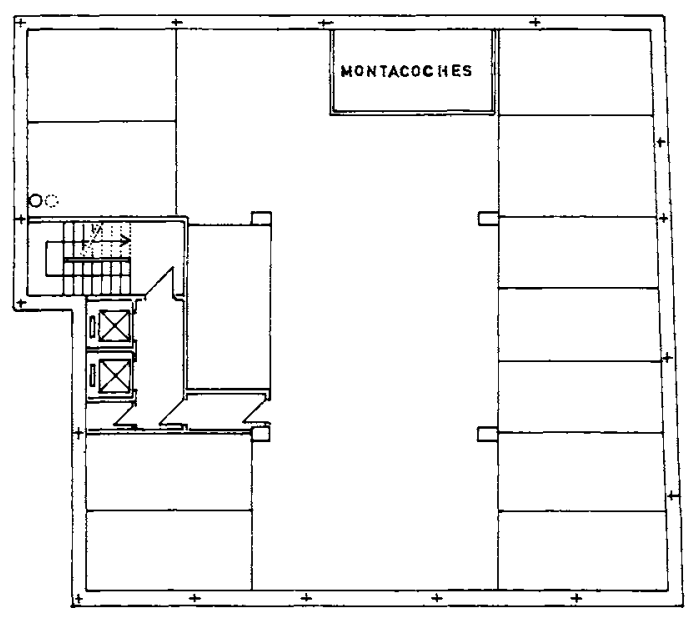

Planta sótanos $2 .^{\circ}$ y $3^{\circ}$
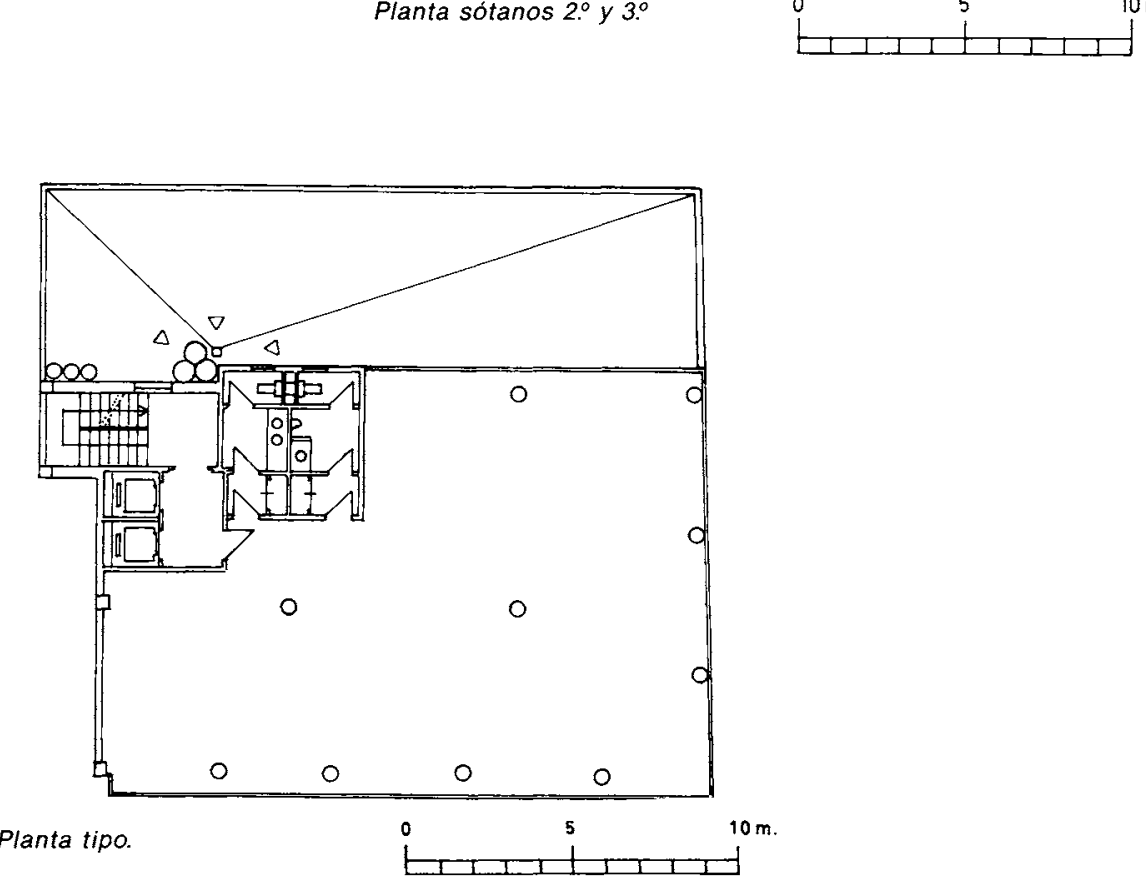
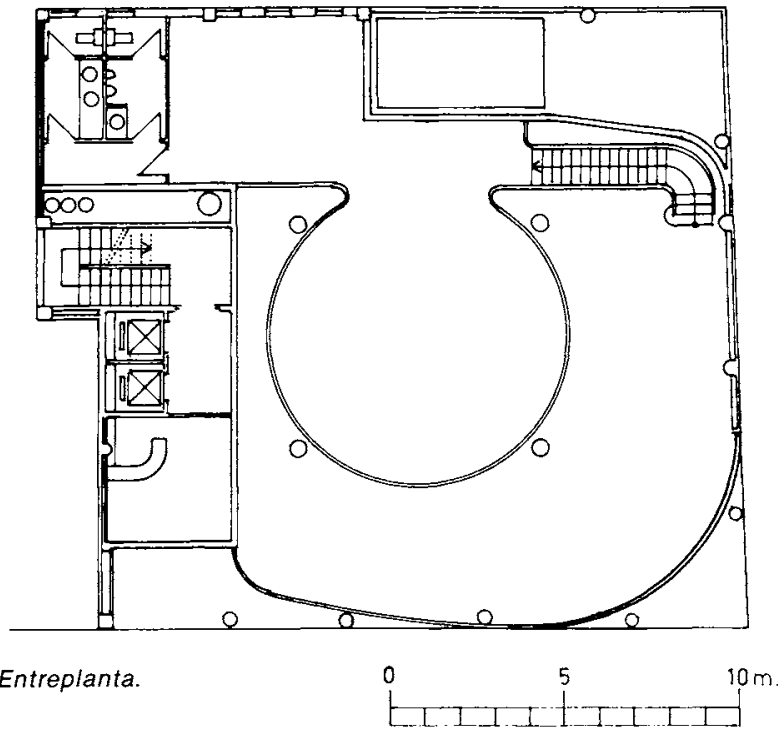

Entreplanta.

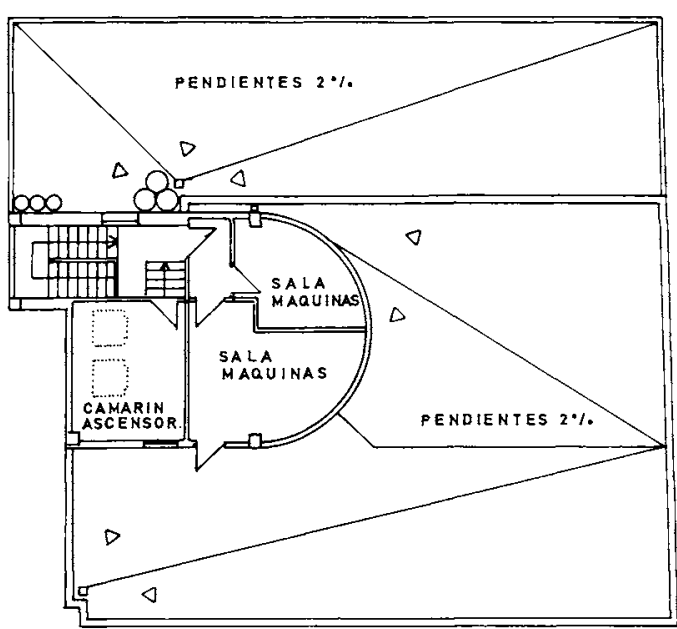

Planta de cubiertas.

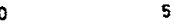

5

http://informesdelaconstruccion.revistas.csic.es 


\section{Materiales empleados}

- Estructura de hormigón armado.

- Fachada muro cortina de perfiles de aluminio lacado, ocultos con silicona estructural a cuatro caras y vidrio color bronce $(6 \mathrm{~mm}-12 \mathrm{~mm}-6 \mathrm{~mm})$.

- Pavimento del portal de granito pulido negro de Sudáfrica; escalera y vestíbulo de ascensores de granito pulido color gris.

- Los revestimientos del portal son de mármol Makael blanco y los de los aseos de granito gris pulido.

- El pavimento de las oficinas es de moqueta.

- Los falsos techos son de chapa metálica perforada, practicables con luminarias empotradas.

\section{Instalaciones importantes}

- Aire acondicionado por bombas de calor, agua-aire repartidas por la fachada, conectadas a un circuito cerrado de agua a dos tubos. Cada acondicionador está compuesto por un grupo motocompre. sor rotativo, un equipo de ventilación y sistema de regulación automática.

Los acondicionadores de aire han sido creados para proporcionar, indistintamente, refrigeración y calefacción de forma automática, gracias al termostato y las válvulas inversoras de ciclo que incorporan, pudiendo atender de esta forma las necesidades de confort que puedan precisar las distintas fachadas. El calor absorbido por los acondicionadores es incorporado al circuito hidráulico general del Edificio, produciéndose una mezcla de agua a distinta temperatura y manteniéndolo dentro de unos límites que permita el enfriamiento o calentamiento del agua por cualquier unidad.

Cuando la temperatura del circuito hidráulico desciende por debajo del mínimo fijado, se ponen en marcha de forma escalonada las calderas, reguladas de forma automática por una sonda de temperatura. Asimismo, si la temperatura del agua supera el valor máximo fijado, una sonda de temperatura actúa sobre las vál. vulas de tres vias, dando paso al agua por el circuito de la torre de enfriamiento.

La instalación se complementa finalmente con un sistema de regulación de tipo electrónico, lo que permite su centralización y mando desde un panel central que incorpora las funciones de regulación, supervisión, control, puesta en marcha y parada optimizada por unas zonas y programas de ahorro energético.

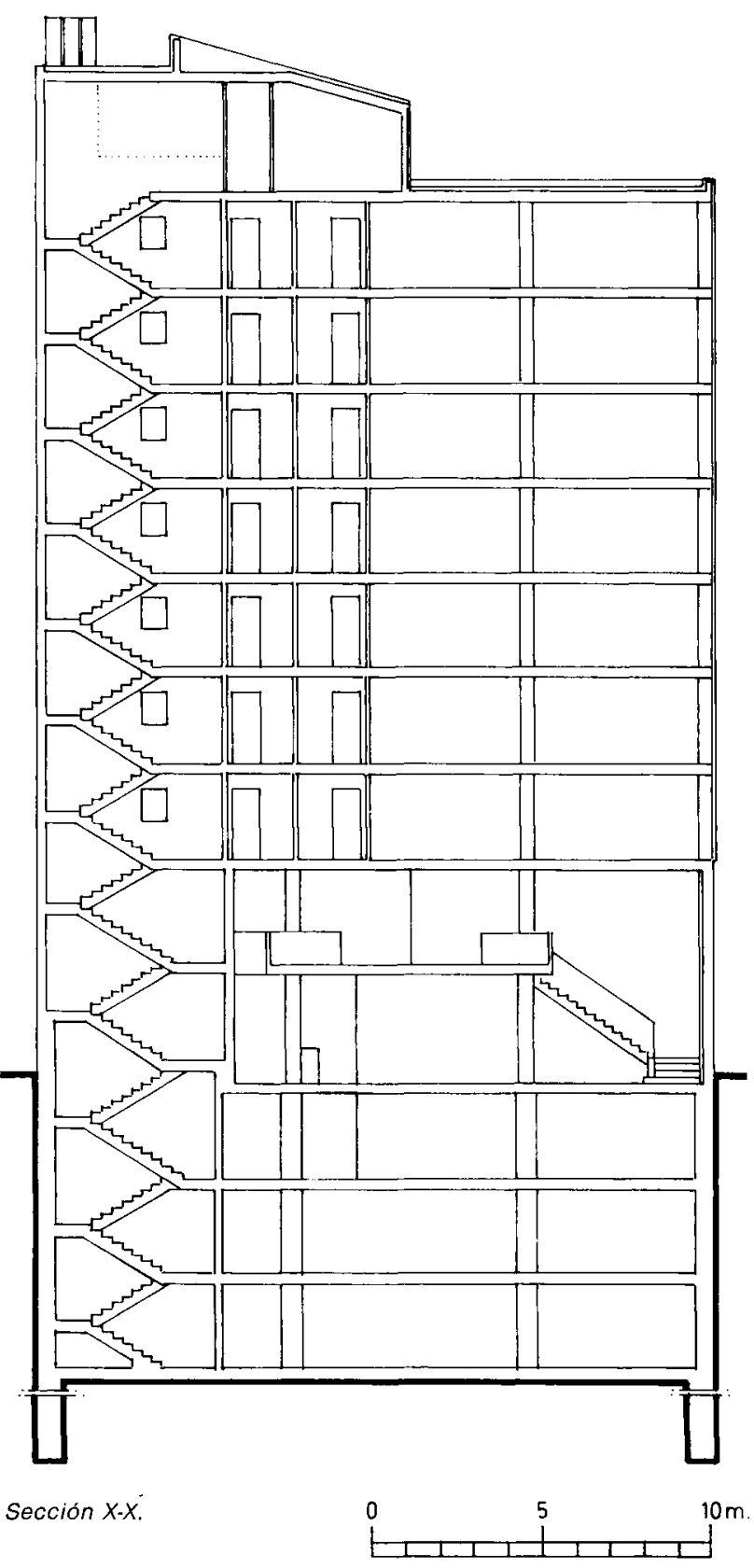

Instalación eléctrica en falsos techos precticables y por canaletas embebidas en el forjado con distribución de energía eléctrica, teléfono y redes informáticas.

Ascensores de $1 \mathrm{~m} / \mathrm{s}$ de velocidad, micronivelación, maniobra combinada, sistema de regulación automática, manual y memoria. Las cabinas son de acero inoxidable y van revestidas en su interior por una serie de espejos que dan sensación de aumentar la capacidad del espacio debido a la repetición de imágenes.

Grupo electrógeno. Detección de monóxido de carbono. Detección y extinción de incendios. Grupo de presión y algibe. 


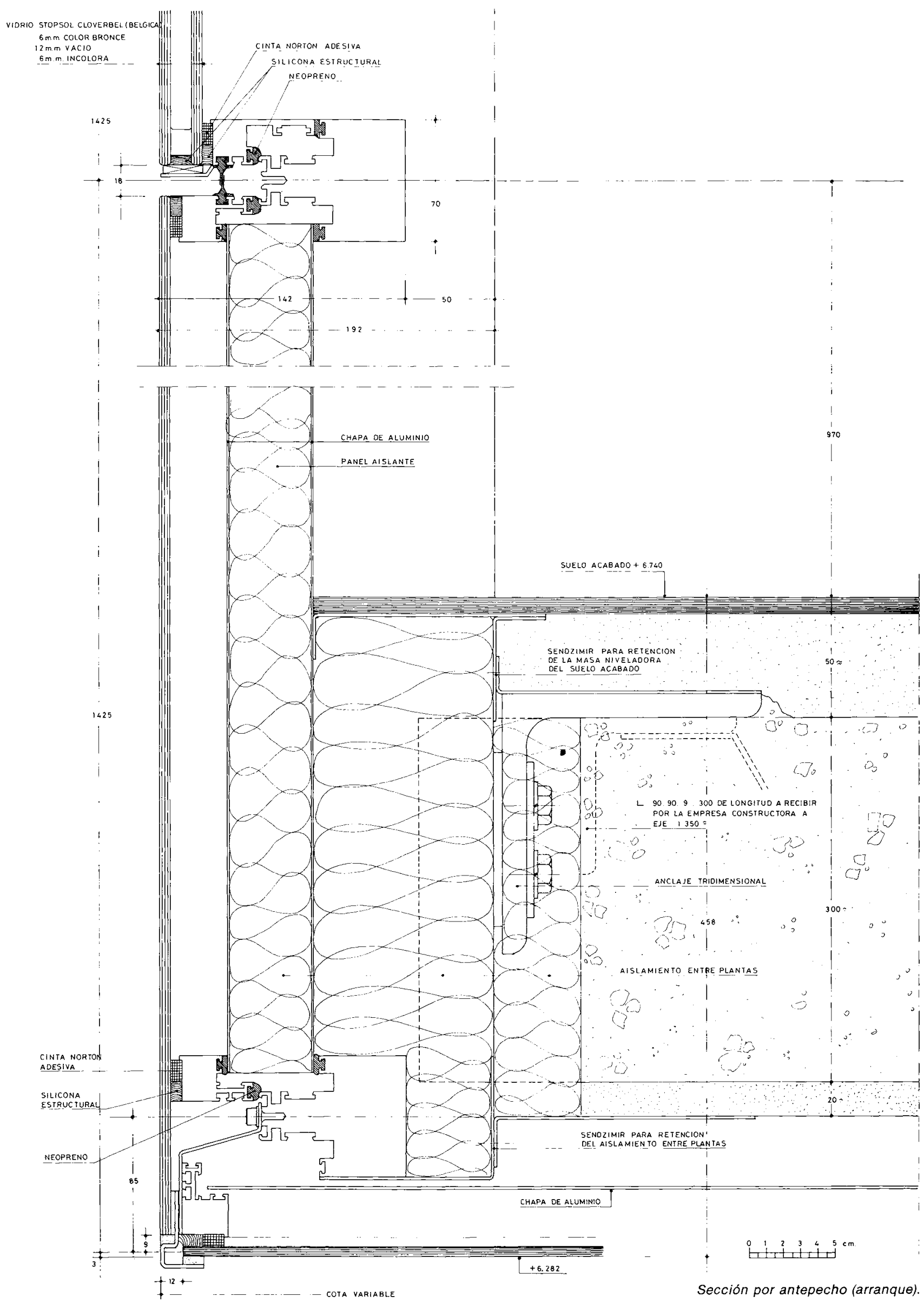




\section{Grado de inteligencia del Edificio}

Tiene un sistema inteligente de control de instalaciones, comunicado por fibra óptica y conectado telefónicamente para su mantenimiento.

Mediante un sistema Experto Robot-4000 son controladas las instalaciones de climatización, alumbrado, presión de agua, ventilación, grupo electrógeno, detección de monóxido de carbono y detección y extinción de incendios de forma automática y racional.

El quipo central está formado por un ordenador, un teclado, dos monitores (color y monocromo), una impre. sora, una fuente de alimentación interrumpida, un distribuidor de fibra óptica, y un conversor de señales.
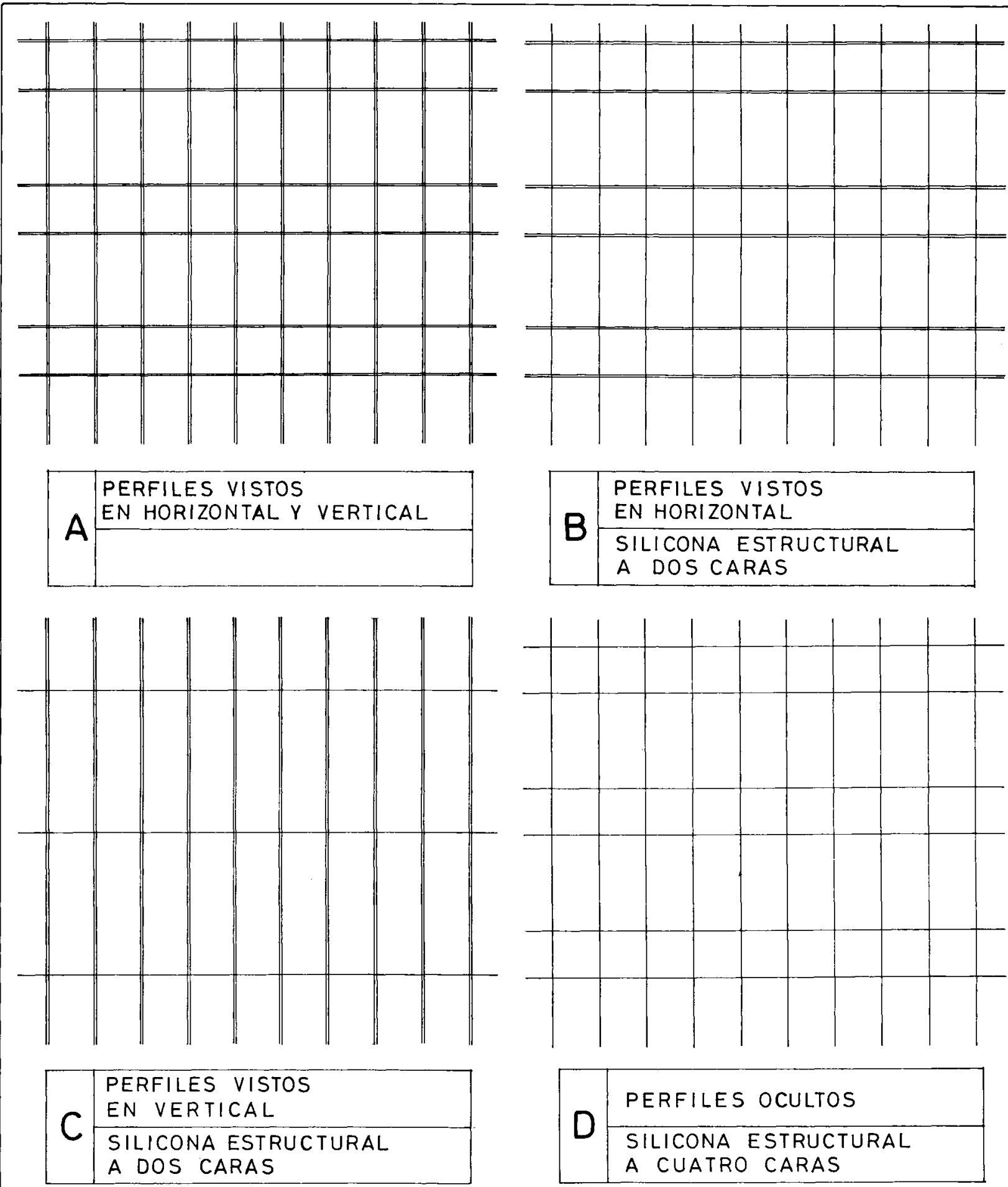